\title{
Pseudoartrosis séptica de tibia por pseudomona aeruginosa. Tratamiento mediante transporte óseo.
}

DOI: http//dx.doi.org/10.37315/SOTOCAV202028455131

FERRANDO-MESEGUER E1, SEGURA-LLOPIS F1, ALMEIDA-HERRERO FL1, TEJEDA-GÓMEZ A1, MIFSUT-MIEDES D 1,2. 1. SERVICIO DE CIRUGÍA ORTOPÉDICA Y TRAUMATOLOGÍA. HOSPITAL CLÍNICO UNIVERSITARIO DE VALENCIA.

2. DEPARTAMENTO DE CIRUGÍA. UNIVERSITAT DE VALÈNCIA.

\section{Resumen.}

La pseudoartrosis séptica continúa siendo un reto para los cirujanos ortopédicos. Su resolución es compleja, con elevada morbilidad y requiriendo un abordaje multidisciplinar. La tibia distal es una localización habitual debido a su escasa vascularización y cobertura cutánea. El tratamiento consistirá en la resección del foco de pseudoartrosis y posterior resolución del defecto tibial. Presentamos el caso de un paciente con pseudoartrosis séptica de tibia que fue tratado mediante resección y transporte óseo con fijador externo. Se consiguió el contacto en la zona de ataque a los 5 meses. Para favorecer la consolidación se aportó injerto de cresta ilíaca autóloga, curetaje y microperforaciones. A los 12 meses se retiró el fijador externo tras consolidación completa. Como única complicación el paciente sufrió dos episodios de celulitis que se resolvieron con antibioterapia.

Palabras clave: Pseudoartrosis tibial, Defectos óseos, Transporte óseo, Fijación externa, Pseudomona Aeruginosa.

\section{Summary.}

Septic non union has still been a challenge for orthopedic surgeons. Its resolution is complex and has hight morbility. It needs a multidisciplinary approach. Distal tibia is a common location due its poor vascularity and soft tissues. We present a patient with pseudoarthrosis of the tibia treated with resection and bone transport. Contact was achieved at the docking site at 5 months. Bone grafting and freshening of fracture ends was performed. At 12 months the frame was removed after complete consolidation. As the only complication, the patient suffered two episodes of cellulitis that were resolved with antibiotic therapy.

Correspondencia:

Emilio Ferrando Meseguer

eferrandomeseguer@gmail.com 


\section{Introducción}

La pseudoartrosis séptica continúa siendo un importante reto para los cirujanos ortopédicos, ya que su resolución es altamente compleja, con elevada morbilidad, y requiere un abordaje multidisciplinar. El auge de las técnicas de osteosíntesis de fracturas ha llevado aparejado un incremento en los índices de procesos infecciosos que interfieren el proceso normal de curación de la fractura.

La incidencia de pseudoartrosis se estima en torno al 3-4\%, con una media de 1,5 intervenciones para pseudoartrosis asépticas y 3,4 intervenciones para las infectadas. La localización suele ser en los huesos largos, siendo el fémur, la tibia y el húmero los más afectados ${ }^{1}$.

La tibia distal es una localización con altas tasas de pseudoartrosis debido principalmente a su escasa vascularización y cobertura cutánea. Por ello las lesiones en esta localización deben de ser tratadas con una indicación quirúrgica adecuada y con un trato cuidadoso de las partes blandas.

Existen variedad de soluciones quirúrgicas para la resolución de defectos tibiales que incluyen osteosíntesis con placa e injerto de hueso esponjoso, acortamiento óseo, tibialización del peroné, microcirugía de reconstrucción con injerto de peroné vascularizado, método de llizarov, técnica de la membrana inducida de Masquelet, sustitutos óseos, células madre o terapia génica ${ }^{2}$.

llizarov en 1971 introdujo su método de transporte óseo, realizando tracción-compresión lenta y controlada (1 $\mathrm{mm} /$ día), estimulando así la osteogénesis. La fijación estable y elástica, así como, la conservación vascular, del periostio, el endostio y la médula ósea fueron fundamentales para alcanzar la consolidación ${ }^{3}$.

Actualmente la resección radical y el transporte óseo es una de las técnicas utilizadas en casos seleccionados.

\section{Caso clínico}

Paciente varón de 67 años que sufrió una fractura abierta de tibia y peroné causada por un accidente de tráfico hacía treinta años. La fractura consolidó con una deformidad en valgo y requirió injerto cutáneo para cobertura de partes blandas. Con el paso de los años desarrolló una gonartrosis. Se inició tratamiento en su hospital de referencia, primero de manera conservadora, con infiltración intraarticular de ácido hialurónico con mejoría parcial, pero ante la progresión del proceso degenerativo y persistencia del dolor, se decidió realizar una osteotomía varizante para corregir la deformidad previa y fijación con clavo intramedular.
Durante la cirugía no fue posible la osteosíntesis con clavo intramedular Trigen posiblemente por la resistencia de la zona de callo de fractura. Por ese motivo se realizó fijación con placa Synthes ${ }^{\circledR}$ LCDCP de 8 orificios.

A los diez días de la intervención la herida presentó tumefacción, flictenas y zonas de necrosis seca. Se inició antibioterapia con Cefuroxima $500 \mathrm{mg} / 12 \mathrm{~h}$ y se continuó con curas locales.

Tras 3 meses de evolución tórpida de la herida quirúrgica a pesar del tratamiento, se remitió a nuestro Centro para valoración por Cirugía Plástica. A su llegada se objetivó defecto cutáneo de $5 \times 8 \mathrm{~cm}$ en tercio distal de cara anterior de tibia derecha, con exposición ósea.

Se tomaron muestras de cultivo con crecimiento de $\mathrm{P}$. Aeruginosa y se cambió la antibioterapia por Linezolid y Ciprofloxacino. Siguiendo curas de la herida y terapia VAC.

A los 5 meses de la osteotomía varizante comentaron el caso con nuestro Servicio, con sospecha diagnóstica de pseudoartrosis séptica tibial (Fig. 1). Decidiéndose la realización de cirugía conjunta con cirugía plástica para resección de pseudoartrosis séptica y cobertura cutánea.
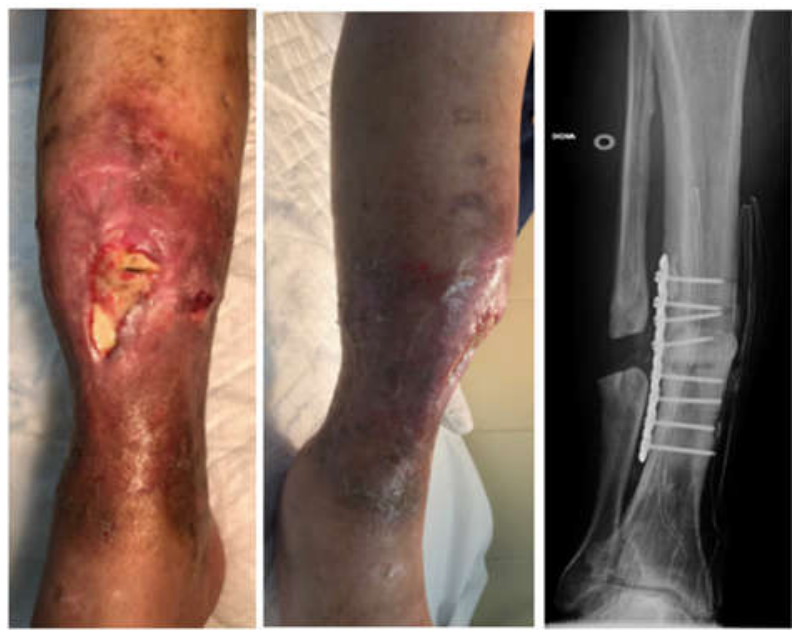

FIGURA 1. Imágenes clínicas y radiológicas del paciente a su llegada a nuestro servicio.

En una primera intervención se realizó la extracción de placa y tornillos y se colocó un fijador externo monolateral. En el mismo acto se procedió a la resección del tejido afecto por la pseudoartrosis hasta obtención de hueso sano y desbridamiento de partes blandas (Fig. 2). Colocación de terapia de vacío con instilación y vendaje compresivo. 


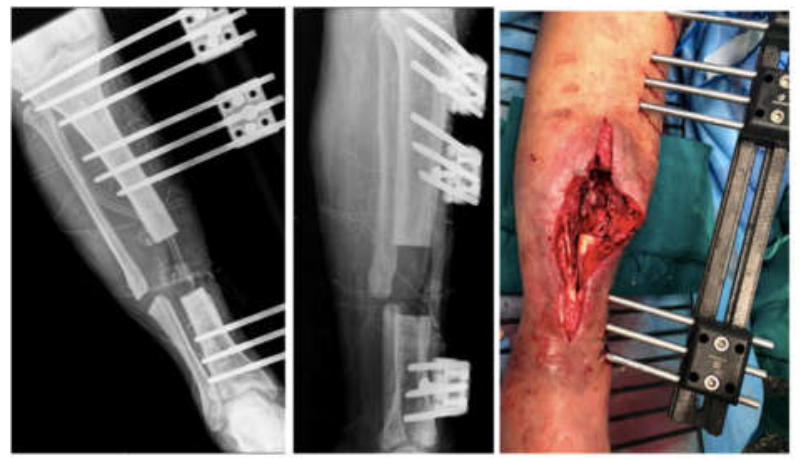

FIGURA 2. Radiografías de control e imagen clínica tras resección de foco de pseudoartrosis y colocación de fijador externo monolateral.

Dos semanas después se realizó la osteotomía en tercio proximal de tibia para permitir el transporte óseo. El paciente inició transporte del fragmento a razón de un milímetro diario a los siete días de la osteotomía.

El contacto de fragmentos en zona de ataque se produjo transcurridos 5 meses desde inicio de transporte. Se realizó nueva intervención con osteotomía de corticales, curetaje del hueso y microperforación, así como adición de injerto autólogo de cresta ilíaca (Fig. 3). Con la ayuda del equipo de cirugía plástica se realizó un colgajo sural reverso para la cobertura de partes blandas.

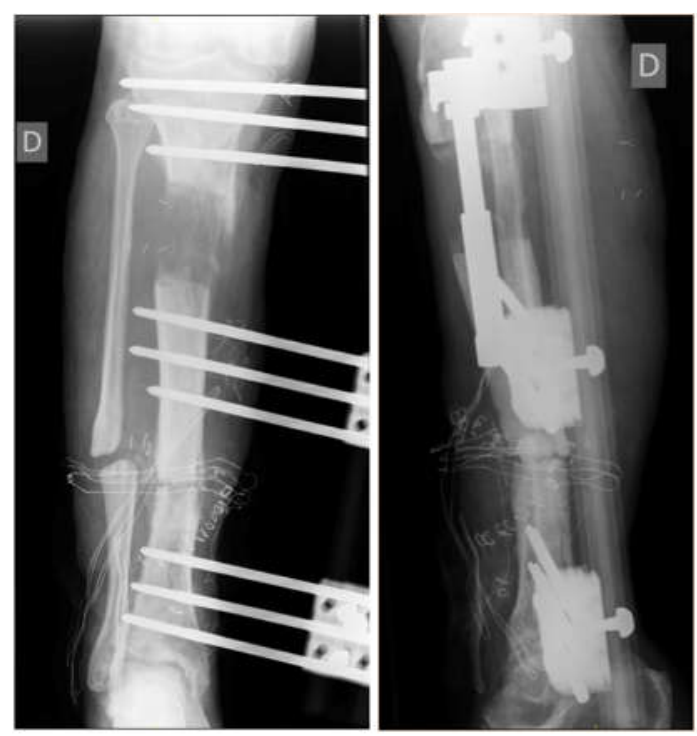

FIGURA 3. Control postquirúrgico tras intervención sobre zona de ataque, en la que se añadió injerto óseo autólogo y se realizó curetaje y microperforaciones.

Presentó dos episodios de celulitis cutánea en región tibial. El microorganismo causante fue S. Pyogenes. El paciente fue hospitalizado y se inició antibioterapia intravenosa con Linezolid y Levofloxacino. En las dos ocasiones el cuadro se resolvió sin complicaciones.
La consolidación definitiva se observó radiológicamente a los 12 meses. Se procedió a retirada de fijador externo y colocación de órtesis tipo polaina funcional personalizada (Fig. 4).
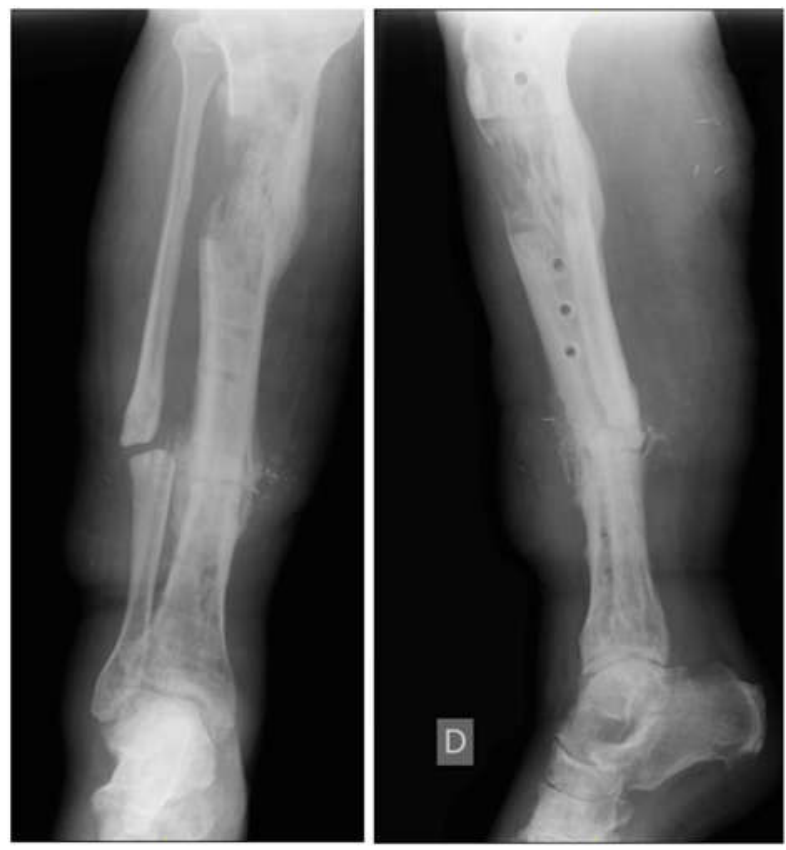

Figura 4. Radiografía tras retirada del fijador externo en la que se aprecia la consolidación en la zona de ataque.

Actualmente tras 24 meses de seguimiento, el paciente deambula sin necesidad de apoyos externos (Fig. 5). Flexión de rodilla $100^{\circ}$ y extensión $-5^{\circ}$ (Fig. 6).
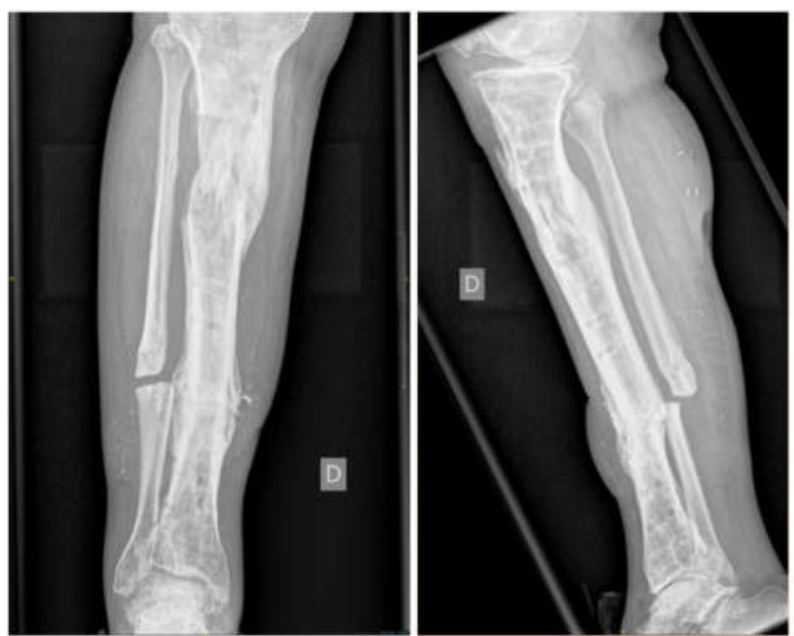

Figura 5. Control a los 18 meses desde inicio de transporte óseo con consolidación completa. 

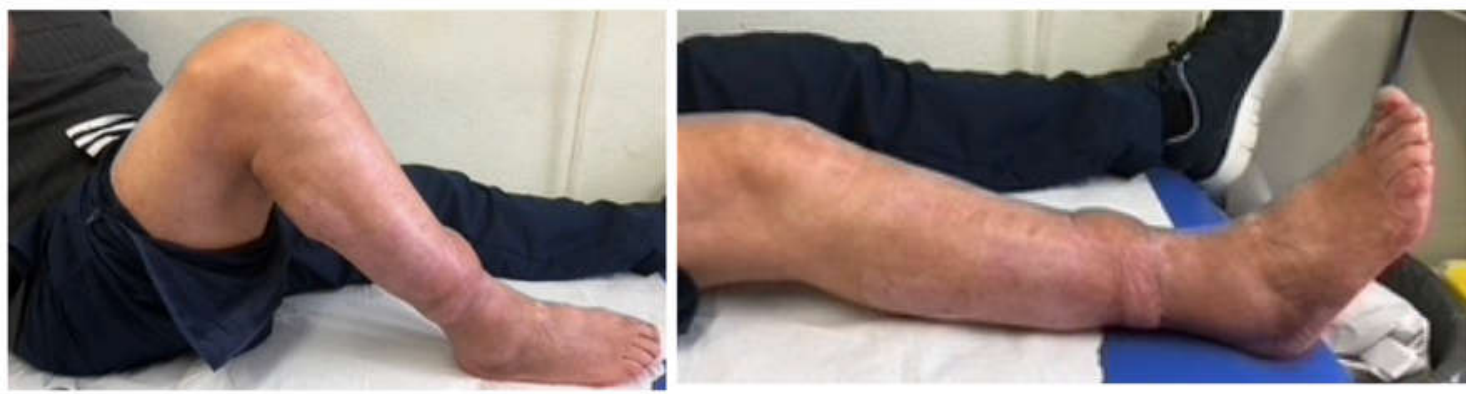

Figura 6. Aspecto clínico a los 24 meses de tratamiento, se ve el rango de movilidad articular de la rodilla.

\section{Discusión}

La pseudoartrosis séptica es una temida complicación, dado que, en casos de tórpida evolución podría conllevar hasta la amputación del miembro. Cuando se localiza en la tibia suele asociarse a fracturas abiertas con gran afectación de la cobertura cutánea ${ }^{1,4}$. El tratamiento de estos defectos es prolongado y agotador para el cirujano y el paciente, y está plagado de complicaciones ${ }^{5}$.

En el caso que presentamos se originó al intentar corregir una secuela de una fractura abierta de tibia y peroné. A pesar de que la fractura consolidó, dejó como secuela una angulación tibial en valgo, que con el paso de los años generó una artrosis de rodilla.

El intento de corrección de dicha secuela derivó en una pseudoartrosis séptica.

El transporte óseo tiene unas indicaciones muy precisas, y se indica en aquellos casos en los que no existen otras posibilidades, en nuestro caso, el defecto óseo de $6 \mathrm{~cm}$ justificó su indicación.

Los objetivos en el tratamiento de los defectos óseos segmentarios son: restaurar la anatomía del hueso, conservar su longitud y recuperar la función ${ }^{6}$.

El método de transporte óseo se basa en un principio fundamental que es la inducción de la osteogénesis en distracción de fragmentos óseos, lo que busca la formación de tejido óseo de excelente calidad biológica, donde traslada un segmento de hueso en dirección longitudinal, bajo los principios de tensión-estrés, permitiendo dicho procedimiento ${ }^{4}$.

Existen otras opciones quirúrgicas ampliamente utilizadas para el tratamiento de defectos óseos segmentarios. El método de Papineau ${ }^{7}$ descrito en los años 70 consiste en resecar el foco de pseudoartrosis y tras un período ventana para la esterilización del foco, rellenar la cavidad. Se utiliza injerto óseo autólogo, dejando expuesto el lecho que se cubre con gasas dejando la cicatrización por segunda intención. Gracias a las terapias VAC en los últimos años se han obtenido mejores resultados.

Otra técnica muy popular es la de Masquelet ${ }^{8}$ de la membrana inducida. Se reseca el foco y se coloca un espaciador de cemento. Alrededor del cemento se crea una membrana de colágeno tipo 1 y fibroblastos. En una segunda fase se abre la membrana, se retira el cemento y se sustituye por injerto óseo, cerrando de nuevo la membrana. La membrana protege la reabsorción del injerto y aporta factores de crecimiento y vascularización.

Si afrontamos defectos de mayor tamaño, otra opción son los injertos óseos vascularizados. El más popular es el injerto de peroné descrito por Taylor ${ }^{9}$. Como ventajas permite conservar la longitud y tiene gran resistencia, además tiene su propia vascularización.

Los aloinjertos óseos estructurales presentan el inconveniente de su difícil consolidación en el tejido óseo huésped $^{10}$.

Las ventajas de utilizar la osteogénesis por distracción para la reconstrucción de defectos óseos segmentarios incluyen la eliminación de necesidad de grandes autoinjertos, riesgo mínimo de daño adicional a los tejidos blandos, capacidad para carga axial durante la reconstrucción, realización del transporte de forma ambulatoria y, lo más importante, la ausencia de límites con respecto al tamaño del defecto que puede ser reconstruido. Además permite su modificación para ajustes de longitud o angulación $n^{2,11}$.

La principal desventaja es el tiempo necesario para la reconstrucción y la carga psicológica para los pacientes. Las desventajas adicionales incluyen la fijación externa prolongada, infecciones frecuentes del tracto de los clavos, el riesgo de una fractura del hueso regenerado y la posibilidad de deformidad después de la extracción del fijador ${ }^{2}$.

Algunos aspectos técnicos a valorar antes de la realización de esta técnica es la localización de la corticotomía. Debe realizarse en la región metafisaria por presentar mejor vascularización y potencial de curación ${ }^{11}$.

El período de latencia para iniciar la distracción se considera entre 3 y 10 días. La presencia de otros factores como inmunosupresión, comorbilidades o infección puede aumentarlo hasta los 14 días $^{11}$. En nuestro caso la distracción se inició a los 7 días. 
La velocidad de distracción más ampliamente aceptada es de $1 \mathrm{~mm}$ por día ${ }^{12}$. Se realiza 4 veces al día con aumentos de 0 ' $25 \mathrm{~mm}^{11}$.

Aktuglu y cols. ${ }^{13}$ realizaron una amplía revisión bibliográfica de trabajos que recogían el tratamiento de defectos óseos tibiales con transporte óseo. En sus resultados destacan la mayor afectación del sexo masculino con un ratio 5:1. La media de los defectos óseos fue de $66^{\prime} 58 \mathrm{~cm}$ con una duración media del fijador de 10'8 meses (2'5-22'3).

En la mayoría de casos se utilizan procedimientos adicionales para conseguir la consolidación en la zona de ataque (docking site). En muchas ocasiones, de forma rutinaria se aporta injerto óseo, se refrescan los bordes óseos o se retiran tejidos blandos interpuestos en esta zona cuando se produce el contacto. Otros gestos como osteosíntesis con placa o clavo pueden ser añadidos en casos de no unión ${ }^{13}$.

Existen publicaciones que ofrecen alternativas al aporte de hueso autólogo. El uso de BMP-7 en el área de ataque del transporte ofrece tasas de consolidación similares, evitando la morbilidad de la zona donante ${ }^{6}$.

De forma tradicional se ha realizado el transporte de forma bifocal, pero existen técnicas trifocales (TFT). Se recomiendan para defectos óseos mayores de $8 \mathrm{~cm}$. Ha sido desarrollada para acortar el tiempo de transporte con la realización de dos osteotomías. Requiere un ensamblaje más complejo del fijador y la realización de una osteotomía adicional $^{5}$

La TFT aumentaría las complicaciones relacionadas con los alambres, las medias clavijas y los sitios de distracción, pero la regeneración más rápida del hueso y la extracción relativamente temprana del marco habrían reducido la tasa de complicaciones ${ }^{5}$.

El desbridamiento agresivo y completo del tejido séptico es la clave para un resultado exitoso al proporcionar un tejido sano con hueso sangrante. Los antibióticos son necesarios por su efecto bactericida ${ }^{12}$. Por este motivo siempre que afrontamos el tratamiento de una pseudoartrosis séptica se requerirá un manejo multidisciplicar.

Para concluir, a pesar de la dificultad y de las posibles complicaciones, con la técnica de transporte óseo se obtienen tasas de consolidación cercanas al 100\%. Por este motivo es una técnica segura para la resolución de defectos óseos tibiales de gran tamaño.

\section{Bibliografía}

1. Vaquero Martín F. Manual del residente de C.O.T de la SECOT. Editorial SECOT; 2014.

2. Aktuglu K, Günay H, Alakbarov J. Monofocal bone transport technique for bone defects greater than $5 \mathrm{~cm}$ in tibia: our experience in a case series of 24 patients. Injury 2016; 47:S40-S46.

3. Ilizarov GA. Transosseous osteosynthesis. Springer. Berlin, Heidelberg, New York, 1992.

4. Laborda Olivera H, Viacava Siazaro F, Noria A, Rey Nande R. Tratamiento de defectos masivos de tibia. Técnica de transporte óseo con fijador AO. Anales de la Facultad de Medicina 2018; 5(2):130-40.

5. Catagni M, Azzam W, Guerreschi F, Lovisetti L, Poli P, Khan M et al. Trifocal versus bifocal bone transport in treatment of long segmental tibial bone defects. The Bone \& Joint Journal 2019; 101-B(2):162-9.

6. Luna González F, Delgado Rufino B, Queipo de Llano Temboury A, Santos De La Fuente J, Quirante Sánchez V. Uso de BMP-7 en el tratamiento de los defectos óseos segmentarios en tibia por osteogénesis a distracción mediante transporte óseo. Estudio prospectivo aleatorizado comparativo entre la BMP-7 y el injerto autólogo. Rev Esp Cir Ortop Traumatol 2010; 54:1923.

7. Papineau LJ, Alfageme A, Dalcourt JP, Pilon L. Ostéomyélite chronique: excision et greffe de spongieux à l'air libre après mises à plat extensives. Int Orthop 1979; 3(3):165-76

8. Masquelet AC, Fitoussi F, Begue T, Muller GP. [Reconstruction of the long bones by the induced membrane and spongy autograft]. Ann Chir Plast Esthet 2000; 45(3):346-53.

9. Taylor GI, Miller GD, Ham FJ. The free vascularized bone graft. A clinical extension of microvascular techniques. Plast Reconstr Surg 1975; 55(5):533-44.

10. Delgado del Caño C, García López J, Rodríguez de Oya R. Pseudoartrosis séptica. Actualización en manejo y tratamiento. Rev Esp Traum Lab 2019; 2(1).

11. Millonig K, Hutchinson B. Management of Osseous Defects in the Tibia. Clinics in Podiatric Medicine and Surgery 2021 38(1):111-6.

12. Karargyris $\mathbf{O}$, Polyzois V, Karabinas $\mathbf{P}$, Mavrogenis A, Pneumaticos $\mathbf{S}$. Papineau debridement, llizarov bone transport, and negative-pressure wound closure for septic bone defects of the tibia. Eur J Orthop Surg Traumatol 2013; 24(6):1013-7.

13. Aktuglu K, Erol K, Vahabi A. Ilizarov bone transport and treatment of critical-sized tibial bone defects: a narrative review. J Orthop Traumatol 2019; 20(1):22. 